\title{
Soxhlet-dialysis: a method to recover soluble polymer supported catalysts $\dagger$
}

\author{
Uche K. Anyanwu and D. Venkataraman*
}

Received 9th February 2005, Accepted 12th April 2005

First published as an Advance Article on the web 22nd April 2005

DOI: $10.1039 / b 501826 a$

Soxhlet-dialysis is used to facilitate the recovery and reuse of a PEG-supported titanium-salen catalyst for the asymmetric silylcyanation of benzaldehyde - up to five times without any loss in activity or enantioselectivity.

There is a widespread interest in developing methods to recover homogeneous catalysts, particularly chiral catalysts, from a reaction mixture. ${ }^{1}$ The impetus to recover and reuse homogeneous catalysts stems not only from an economic standpoint but also from the need to eliminate contamination of the transition metal catalyst in the product and in the waste streams. The challenge is to recover the catalyst for reuse without any significant loss in its reactivity and selectivity. ${ }^{2}$ We report here a simple method that we call soxhlet-dialysis for the recovery of soluble polymer supported catalysts. Using this method, we show that a PEG-supported titanium-salen complex can be recovered and reused for silylcyanation of benzaldehyde at least five times without any loss of reactivity and enantioselectivity. When compared with normal dialysis, soxhlet-dialysis minimizes the amount of solvent that is required because of the recycling of the solvent through reflux.

Among the strategies to recycle catalysts, the use of soluble supports to anchor transition-metal complexes has received considerable attention in recent years. ${ }^{3}$ The soluble support ensures that the catalyst is in the same phase as the reactants and reagents. Therefore, the reactivity and selectivity of the catalysts anchored on soluble supports can equal that of the unsupported homogeneous analogs; it is a significant advantage over the catalysts supported on insoluble supports. ${ }^{4}$ Initial methods to recover the catalyst for recycling were focused on precipitation and filtration of the supported catalyst by reducing the solubility of the support using an appropriate solvent ${ }^{5}$ or by changing the temperature. ${ }^{6}$ The precipitated catalyst often shows substantially reduced activity and poor recyclability., ${ }^{2,7}$ More recent methods focus on retaining the catalyst in solution and separating it from the reactants and products. These methods include the use of liquid-liquid biphasic solvent systems ${ }^{8}$ and pressurized-filtration using membranes with nanometer-sized pores. ${ }^{9}$

We have been interested in using dialysis to recover homogeneous polymer-supported catalysts for recycling. ${ }^{10}$ Dialysis relies on a concentration gradient across a semi-permeable membrane and the rate of diffusion declines exponentially as the system approaches equilibrium. In order to re-establish the diffusion gradient, the bulk needs to be periodically replaced with fresh solvent. ${ }^{11}$ Therefore, using dialysis to recover catalysts would require large amounts of solvent. To address this issue, we

$\uparrow$ Electronic supplementary information (ESI) available: experimental details for the synthesis of the PEG-supported catalyst, characterization data and dialysis/UV-vis experiments for the PEG-dye. See http:// www.rsc.org/suppdata/gc/b5/b501826a/

*dv@chem.umass.edu
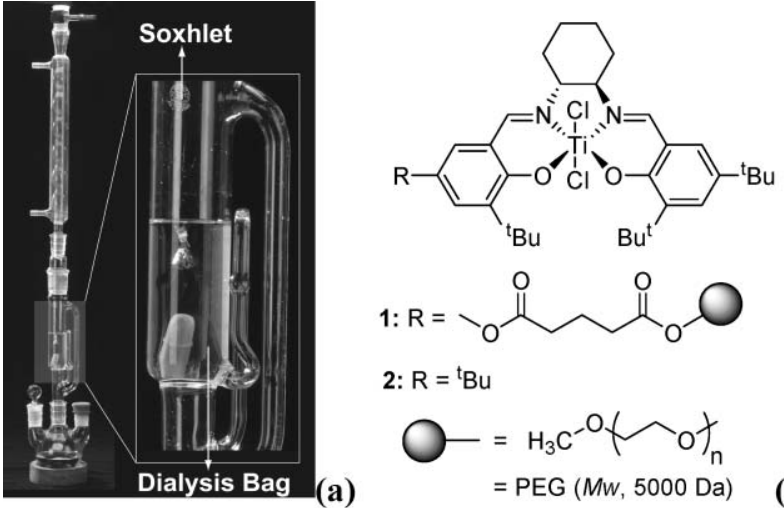

2: $\mathrm{R}={ }^{\mathrm{t}} \mathrm{Bu}$

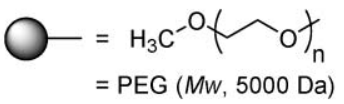

(b)

Fig. 1 (a) Soxhlet-dialysis apparatus. (b) PEG-supported Ti-salen catalyst, $\mathbf{1}$, and unsupported catalyst, $\mathbf{2}$.

developed a simple semi-continuous-flow dialysis set up using a soxhlet extractor where the thimble is replaced with a dialysis bag (Fig. 1a). The dialyzed solution outside the membrane is continuously replaced with fresh solvent from the reflux, thereby maintaining the diffusion gradient. Of particular concern is the stability of dialysis membranes to organic solvents. ${ }^{9,12}$ However, we found that commercially available Spectra/Por ${ }^{\circledR}$ regenerated cellulose membranes are stable to most organic solvents over extended periods of time.

We chose the asymmetric silylcyanation of benzaldehyde using a chiral titanium-salen complex as a model reaction. ${ }^{13}$ As the soluble polymeric support, we used polyethylene glycol (PEG, $M_{\mathrm{w}}=$ $5000 \mathrm{Da}$ ), which was attached to the catalyst through a glutaric acid spacer (Fig. 1b). A solution of the PEG-supported salen ligand $^{14}$ in dichloromethane was treated with an equimolar amount of titanium tetrachloride and allowed to stir at room temperature for one hour to give $\mathbf{1}$. The solution of the preformed catalyst $(0.1 \mathrm{~mol} \%$ of $\mathbf{1})$ was treated with equimolar amounts of benzaldehyde and trimethylsilylcyanide (TMCN) (Scheme 1). The reaction proceeded at room temperature and was monitored by GC until complete conversion $(>99 \%)$ of benzaldehyde to the product was observed. The product, cyanohydrin trimethylsilyl ether, was obtained in $86 \%$ ee after $24 \mathrm{~h}$, similar to the previously reported enantioselectivity achieved with the unsupported catalyst 2. ${ }^{13}$ The reaction was concentrated and placed into a dialysis tubing (molecular weight cut-off $=3.5 \mathrm{kDa}$ ) with one end tied shut. A magnetic stir bar was then placed into the dialysis bag to

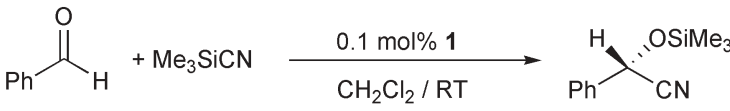

$$
\begin{aligned}
& 100 \% \text { conv } \\
& 86 \% \text { ee }
\end{aligned}
$$

Scheme 1 Asymmetric silylcyanation of benzaldehyde by 1 . 
Table 1 Recovery and change in ee over five runs using 1

\begin{tabular}{lccc}
\hline Runs & ee $^{a}(\%)$ & Conv. $^{b}(\%)$ & Recovery $^{c}(\%)$ \\
\hline 1 & 86 & $>95$ & 98 \\
2 & 85 & $>95$ & 99 \\
3 & 86 & $>95$ & 99 \\
4 & 88 & $>95$ & 98 \\
5 & 85 & $>95$ & - \\
${ }^{a}$ Determined by chiral & GC using a Cyclosil-B ${ }^{\mathbb{R}}$ column. \\
${ }^{b}$ Determined by GC. ${ }^{c}$ Determined by GC against a dodecane \\
internal standard. ${ }^{d}$ Soxhlet-dialysis was carried out in $\mathrm{CH}_{2} \mathrm{Cl}_{2}$ at \\
60
\end{tabular}

prevent it from floating, and the open end of the tubing was tied shut with a string. The bag was then placed into the soxhlet chamber. Dichloromethane was used as the recovery solvent; $25 \mathrm{~mL}$ was placed in the soxhlet chamber, and $100 \mathrm{~mL}$ in the three-necked recovery flask. Dodecane was added to the solvent in the recovery flask as an internal standard in order to allow for quantitative GC analysis of the product in the dialysate. The recovery flask was then placed in an oil bath and was heated to $60{ }^{\circ} \mathrm{C}$. The soxhlet chamber refilled every 20 minutes with fresh solvent from the reflux. After $38 \mathrm{~h}, 98 \%$ of the cyanohydrin trimethylsilyl ether was recovered. (Table 1). Changing the capacity of the soxhlet chamber (by changing the size of the soxhlet apparatus) from $25 \mathrm{~mL}$ to $100 \mathrm{~mL}$ had no effect on the rate of dialysis (see electronic supporting information†).

After each cycle, the contents of the dialysis bag were poured into a round-bottomed flask and treated with fresh benzaldehyde and TMSCN under similar initial reaction conditions; no fresh catalyst was added. Complete conversion to the product was achieved in $24 \mathrm{~h}$. The reaction solution was concentrated and subsequently subjected to another soxhlet-dialysis recovery cycle. The catalyst was recovered and reused for at least five runs without any loss in selectivity or reactivity $(84-86 \%$ ee, $>99 \%$ conv.) (Table 1). It is noteworthy that due to the high substrate-tocatalyst ratio for this reaction, recovery of the PEG-supported catalyst by solvent precipitation is impractical.

Even though the catalyst maintained its activity over multiple runs, it was still necessary to assess extent of retention in the dialysis bag. An ICP analysis of the concentrated bulk solvent did not detect the presence of titanium. We then synthesized PEG attached to $p$-methyl-red. A solution of the PEG-dye in dichloromethane was subjected to a soxhlet-dialysis cycle under the same conditions used in the recovery of $\mathbf{1}$. Samples of the dialysate were taken over a period of $38 \mathrm{~h}$ and analyzed by UV-vis spectrometry. The PEG-dye present in the dialysate was determined to be $3 \%$, reflecting $97 \%$ retention in the dialysis bag. Even after $72 \mathrm{~h}$, the amount of PEG-dye retained in the dialysis bag remained constant (Fig. 2). We attribute the initial loss of PEG-dye to low molecular weight polymeric impurities present in the commercially available PEG. Once the low molecular weight impurities are lost, no further loss of the PEG-dye is observed. Based on the differences in the rates of diffusion between the small molecule product and the polymer-supported catalyst, we believe that the retention of the catalyst is much higher than $97 \%$. This is further supported by the fact that no additional catalyst was required for subsequent runs.

In conclusion, we have developed soxhlet-dialysis as a simple and straightforward method for the recovery of soluble polymersupported catalysts without any loss in its activity. This method

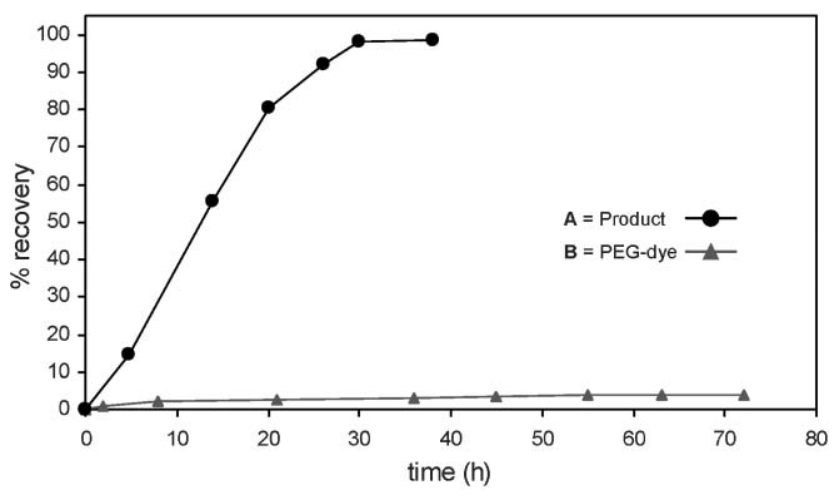

Fig. 2 Retention of PEG-supported catalyst in dialysis bag; (A) recovery of the product cyanohydrin trimethylsilylether (B) recovery of PEG-dye.

employs commercially available dialysis membranes and common laboratory apparatus. Soxhlet-dialysis can be generally applied to recycling of soluble polymer-supported catalysts, without further modification of the original reaction conditions, as well as the purification of soluble macromolecules from low molecular weight impurities.

\section{Acknowledgements}

The University of Massachusetts, Amherst, start-up funds and a Camille and Henry Dreyfus New Faculty Award provided the financial support for this research.

Uche K. Anyanwu and D. Venkataraman*

Department of Chemistry, University of Massachusetts-Amherst, $710 \mathrm{~N}$. Pleasant St., Amherst, MA 01003,USA.E-mail: dv@chem.umass.edu; Fax: 001413545 4490; Tel: 0014135452028

\section{References}

1 (a) Q.-H. Fan, Y.-M. Li and A. S. C. Chan, Chem. Rev., 2002, 102, 3385-3466; (b) D. J. Cole-Hamilton, Science, 2003, 299, 1702-1706.

2 U. Kragl and T. Dwars, Trends Biotechnol, ,2001, 19, 442-449.

3 (a) D. E. Bergbreiter, Chem. Rev., 2002, 102, 3345-3384; (b) T. J. Dickerson, N. N. Reed and K. D. Janda, Chem. Rev., 2002, 102, 3325-3344.

4 (a) M. Lasperas, N. Bellocq, D. Brunel and P. Moreau, Tetrahedron: Asymmetry, 1998, 9, 3053; (b) K. Soai, M. Wantanabe and A. Yamamoto, J. Org. Chem., 1990, 55, 4832.

5 P. Wentworth, Jr. and K. D. Janda, Chem. Commun., 1999, 1917-1924.

6 V. M. Mariagnanam, L. Zhang and D. E. Bergbreiter, Adv. Mater., 1995, 7, 69-71.

7 D. Jayaprakash and H. Sasai, Tetrahedron: Asymmetry, 2001, 12, 2589-2595.

8 D. E. Bergbreiter, S. D. Sung, J. Li, D. Oritz and P. N. Hamilton, Org. Process Res. Dev., 2004, 8, 461-468.

9 H. P. Dijkstra, C. A. Kruithof, N. Ronde, R. van de Coevering, D. J. Ramon, D. Vogt, G. P. M. van Klink and G. van Koten, J. Org. Chem., 2003, 68, 675-685.

10 (a) D. Venkataraman and U. K. Anyanwu, Abstr. Pap. Am. Chem. Soc., 2001, 222, U91-U91. Enzymes and catalysts anchored on dendrimers have been compartmentalized using dialysis membranes. In these cases, mass transport through the membrane is rate-limiting. See; (b) M. D. Bednarski, H. K. Chenault, E. S. Simon and G. M. Whitesides, J. Am. Chem. Soc., 1987, 109, 1283-1285; (c) K. De Smet, A. Pleysier, I. F. J. Vankelecom and P. A. Jacobs, Chem. Eur. J., 2003, 9, 334-338.

11 P. Hess and D. E. Wells, Analyst, 2001, 126, 829-834.

12 A. Wolfson, K. B. Janssen, I. F. J. Vankelecom, S. Geresh, S. Gottlieb and M. Herskowitz, Chem. Commun., 2002, 4, 388.

13 (a) M. North, Tetrahedron: Asymmetry, 2003, 14, 147-176; (b) H. Y. Chen, P. S. White and M. R. Gagne, Organometallics, 1998, 17, 5358-5366; (c) S. J. Coles, M. B. Hursthouse, D. G. Kelly, A. J. Toner and N. M. Walker, J. Chem. Soc., Dalton Trans., 1998, 3489-3494.

14 T. S. Reger and K. D. Janda, J. Am. Chem. Soc., 2000, 122, 6929-6934. 